\title{
Delayed Hypersensitivity Reactions Caused by Drug Excipients: A Literature Review
}

\author{
Caballero ML, Quirce S \\ Department of Allergy, La Paz University Hospital, IdiPAZ, Madrid, Spain
}

J Investig Allergol Clin Immunol 2020; Vol. 30(6): 400-408

doi: 10.18176/jiaci.0562

\begin{abstract}
The European Medicines Agency (EMA) defines excipients as the constituents of a pharmaceutical form apart from the active substance. Delayed hypersensitivity reactions (DHRs) caused by excipients contained in the formulation of medications have been described. However, there are no data on the prevalence of DHRs due to drug excipients. Clinical manifestations of allergy to excipients can range from skin disorders to life-threatening systemic reactions.

The aim of this study was to perform a literature review on allergy to pharmaceutical excipients and to record the DHRs described with various types of medications, specifically due to the excipients contained in their formulations. The cases reported were sorted alphabetically by type of medication and excipient, in order to obtain a list of the excipients most frequently involved for each type of medication.

Key words: Allergy. Delayed hypersensitivity reaction. Drug hypersensitivity reaction. Excipient. Pharmaceutical excipients.
\end{abstract}

\section{Resumen}

La Agencia Europea de Medicamentos define los excipientes como los componentes de una forma farmacéutica diferenciados del principio activo. Se han descrito reacciones de hipersensibilidad retardada causadas por los excipientes contenidos en la formulación de medicamentos. Sin embargo, no hay datos sobre la prevalencia de dichas reacciones. Las manifestaciones clínicas de la alergia a los excipientes pueden ir desde trastornos de la piel hasta reacciones sistémicas que ponen en peligro la vida.

El objetivo de este estudio fue realizar una revisión de la literatura sobre la alergia a los excipientes farmacéuticos y recopilar las reacciones de hipersensibilidad retardada descritas con diferentes tipos de medicamento, debido solo a excipientes contenidos en sus formulaciones. Los casos se clasificaron alfabéticamente por tipo de medicamento y excipiente, con el fin de obtener una lista de los excipientes más frecuentemente implicados con cada tipo de medicamento.

Palabras clave: Alergia. Excipiente. Excipientes farmacéuticos. Reacción de hipersensibilidad retardada. Reacciones de hipersensibilidad a medicamentos. 


\section{Introduction}

The European Medicines Agency (EMA) defines excipients as the constituents of a pharmaceutical form apart from the active substance [1]. From a pharmaceutical point of view, an excipient is an inert substance added to a drug to change solubility or the kinetics of absorption, improve stability, influence palatability, or create a distinctive appearance. Hypersensitivity reactions to excipients may lead to a falsepositive diagnosis of drug allergy [2].

The aim of this study was to perform a literature review on delayed hypersensitivity reactions (DHRs) to pharmaceutical excipients by using the electronic search engine PubMed/ MEDLINE to identify potentially relevant studies published in peer-reviewed journals until December 2019. The cases were sorted alphabetically by type of medication and excipient in order to obtain a list of the most frequently involved excipients for each type of medication.

\section{DHRs Due to Excipients Reported With Various Types of Medications}

The excipients involved in the DHRs described in this review article are shown in Tables 1 and 2. A link to the PubChem Database of the National Center for Biotechnology Information (NCBI-PCD) for the description of each excipient (Table 3 ) and a summary of the concentrations used to test each excipient (Table 4) are provided.

\section{Antiepileptic Drugs}

\section{Carboxymethylcellulose}

DHRs to unrelated products due to carboxymethylcellulose (CMC) have been reported [3] (Table 2). A patient who developed drug reaction with eosinophilia and systemic symptoms (DRESS) syndrome caused by carbamazepine (Tegretol, CMC-containing) subsequently experienced eczematous rashes following the intake of pills containing paracetamol and a nonsteroidal anti-inflammatory drug (NSAID). Because the results of both the patch test and the skin prick test (SPT) were negative for CMC, an oral provocation test with a cumulative dose of $1.115 \mathrm{mg}$ of CMC was performed under hospital surveillance. The patient developed a generalized eczematous rash on the following day.

\section{Antihistamines}

\section{Propylene Glycol}

Propylene glycol (PG), an emollient and emulsifier found in cosmetics, medications, and food, was granted the dubious honor of being named the American Contact Dermatitis Society's Allergen of the Year for 2018. Contact, systemic, and irritant cutaneous reactions have been documented for this allergen. Optimal patch test concentrations and reading intervals have been a topic of debate for many years because PG causes both irritant contact dermatitis and allergic contact dermatitis (ACD), and it is often difficult to differentiate between these types of reactions. The most recent update for the American Contact Dermatitis Society's core series recommends testing only with $100 \%$ PG. The confounding characteristics of patch tests to PG increase the relevance of an accurate interpretation. Crescendo reactions, which show little or no activity at 48 hours but become stronger at 96 hours, suggest contact allergy. Decrescendo reactions, which present weakly at 48 hours but disappear by 96 hours, are probably irritant reactions [4].

In the present review, reactions due to $\mathrm{PG}$ are reported with antihistamines, anxiolytics, lubricants, topical medications, and ultrasound gels.

DHRs with antihistamines and other unrelated products due to PG (Table 2) have also been documented, as follows:

- ACD with positive patch test results to PG. A sensitized patient improved significantly after switching to a PGfree topical corticosteroid. However, since dermatitis flared annually during seasonal rhinitis, it was discovered that the patient used oral antihistamines, which also contained PG [5].

- Eczematous lesions or rash with positive patch test results to PG. Dermatitis improved after switching to a PG-free topical corticosteroid. Two flare-ups of the patient's rash during seasonal use of oral cetirizine syrup led to the discovery that the antihistamine formulation contained PG [6].

- Atopic dermatitis treated with topical corticosteroids and oral antihistamines, without improvement. The patient had a positive patch test result to $\mathrm{PG}$, and the skin lesions resolved after switching to a PG-free hydroxyzine syrup [6].

\section{Anxiolytics}

\section{Propylene Glycol}

DHRs due to PG have been observed with unrelated products [7] (Table 2). The patient experienced systemic contact dermatitis after administration of injectable diazepam (Valium) and with a lubricant K-Y Jelly during a gynecological examination. Both products contained PG. The patch test result to PG was positive.

\section{Corticosteroids}

\section{Benzalkonium Chloride}

Three cases of systemic allergic reactions induced by benzalkonium chloride (BAC) have been described after the use of a mometasone nasal spray. Patient histories and the positive results of the patch tests performed in 2 of the patients point to a diagnosis of type IV hypersensitivity reactions due to BAC [8].

\section{Carboxymethylcellulose}

DHRs reported with unrelated products due to CMC [3] (Table 2) took the form of flexural dermatitis 3 days after an intra-articular injection of a betamethasone dipropionate preparation (CMC-containing) and, a few months later, 
Table 1. Excipients Involved in the Delayed Hypersensitivity Reactions Reported With Different Type of Medications

\begin{tabular}{|c|c|c|c|c|c|c|c|c|}
\hline Type of Medication & Excipient & & & & & & & \\
\hline AEDs & $\mathrm{CMC}$ [3] & & & & & & & \\
\hline Antihistamines & PG $[5,6]$ & & & & & & & \\
\hline Anxiolytics & PG [7] & & & & & & & \\
\hline Corticosteroids & $\mathrm{BAC}[8]$ & $\mathrm{CMC}[3]$ & & & & & & \\
\hline Insulin & $\begin{array}{l}\text { Metacresol } \\
{[10,11]}\end{array}$ & $\begin{array}{l}\text { Zinc } \\
{[12]}\end{array}$ & & & & & & \\
\hline Local anesthetics & $\operatorname{SMB}[13,14]$ & & & & & & & \\
\hline Lubricants & PG [15] & & & & & & & \\
\hline Mineral supplements & $\begin{array}{l}\text { Sunset Yellow } \\
\text { FCF }[16]\end{array}$ & & & & & & & \\
\hline NSAIDs & $\begin{array}{l}\text { Colloidal } \\
\text { silica [17] }\end{array}$ & & & & & & & \\
\hline Ophthalmic products & $\mathrm{BAC}[18,19]$ & $\begin{array}{l}\text { Thimerosal } \\
{[20-23]}\end{array}$ & & & & & & \\
\hline Parenteral medications & $\mathrm{BnOH}[24]$ & & & & & & & \\
\hline \multirow[t]{2}{*}{ Topical medications } & $\begin{array}{l}\text { Ascorbyl } \\
\text { tetraisopalmitate } \\
{[25]}\end{array}$ & $\begin{array}{l}\mathrm{BnOH} \\
{[26]}\end{array}$ & $\begin{array}{l}\text { Cetostearyl } \\
\text { alcohol [27] }\end{array}$ & $\begin{array}{l}\text { Chlorocresol } \\
{[28]}\end{array}$ & $\begin{array}{l}\text { DSS } \\
{[29]}\end{array}$ & $\begin{array}{l}\text { EDTA } \\
{[30]}\end{array}$ & $\begin{array}{l}1,2,6- \\
\text { Hexanetriol } \\
{[31]}\end{array}$ & \\
\hline & $\begin{array}{l}\text { Isopropyl } \\
\text { palmitate [26] }\end{array}$ & $\begin{array}{l}\text { Parabens } \\
{[32]}\end{array}$ & $\begin{array}{l}\text { PEG } \\
{[35-38]}\end{array}$ & $\begin{array}{l}\text { Propyl } \\
\text { gallate [39] }\end{array}$ & $\begin{array}{l}\text { PG } \\
{[28,40]}\end{array}$ & $\begin{array}{l}\text { SMB } \\
{[41]}\end{array}$ & $\begin{array}{l}\text { Sodium } \\
\text { sulfite [42] }\end{array}$ & $\begin{array}{l}\mathrm{SSO} \\
{[44]}\end{array}$ \\
\hline Ultrasound gels & $\begin{array}{l}\text { Imidazolidinyl } \\
\text { urea [45] }\end{array}$ & $\begin{array}{l}\text { MDBGN } \\
{[46,47]}\end{array}$ & $\begin{array}{l}\mathrm{PG} \\
{[48-50]}\end{array}$ & & & & & \\
\hline Vaccines & Formaldehyde [51] & & & & & & & \\
\hline Wound dressings & $\begin{array}{l}\mathrm{CMC} \\
{[3]}\end{array}$ & $\begin{array}{l}\text { Colophonium } \\
{[52]}\end{array}$ & & & & & & \\
\hline
\end{tabular}

Abbreviations: AEDs, antiepileptic drugs; $\mathrm{BAC}$, benzalkonium chloride; $\mathrm{BnOH}$, benzyl alcohol; $\mathrm{CMC}$, carboxymethylcellulose; DSS, dioctyl sodium sulfosuccinate; MDBGN, methyldibromo glutaronitrile; NSAIDs, nonsteroidal anti-inflammatory drugs; PEG, polyethylene glycol; PG, propylene glycol; $\mathrm{SMB}$, sodium metabisulfite; $\mathrm{SSO}$, sorbitan sesquioleate.

maculopapular rash affecting the trunk 24 hours after taking piroxicam pills (CMC-containing). Patch testing to $\mathrm{CMC}$ was negative, although the SPT revealed an infiltrated, erythematous reaction after 24 hours.

\section{Insulin}

DHRs to insulin itself do not appear to have been reported; reactions usually occur to the components added to insulin preparations [9].

\section{Metacresol}

- Injection site reactions have been reported, independently of the type of human insulin used. Patch test results were positive to human, pork, and isophane insulins and to metacresol, which is present in all the insulins tested [10].

- A patient tolerating insulin lispro (Humalog) started using an insulin pump and began to experience itching at the injection sites. The lesions disappeared when the patient returned to injections with insulin aspart (Novolog). Analysis of the insulin compounds revealed that metacresol was present in different doses. Patch testing to metacresol was positive [11].

\section{Zinc}

Local cutaneous hypersensitivity reactions were reported in 2 patients after injection of insulin preparations [12]. The patients reported pruritic, erythematous, papular lesions at the injection site 24 hours after injection. Zinc insulin and zinc sulphate induced transformation and proliferation of peripheral blood lymphocytes from these patients and production of a specific leucocyte inhibitory factor. Intradermal tests to zinc were positive in both cases.

\section{Local Anesthetics}

\section{Sodium Metabisulfite}

- Severe edema of the face and neck developed 2 hours after the injection of a local dental anesthetic (Neo-Lidocaton) containing sodium metabisulfite (SMB), which was not originally declared by the manufacturer [13]. Patch 
Table 2. Excipients Involved in the Delayed Hypersensitivity Reactions Reported With Unrelated Products

\begin{tabular}{|c|c|}
\hline Type of Product & Excipient \\
\hline $\begin{array}{l}\text { Antiepileptic drugs, analgesics, } \\
\text { and NSAIDs }\end{array}$ & $\begin{array}{l}\text { Carboxymethyl- } \\
\text { cellulose [3] }\end{array}$ \\
\hline $\begin{array}{l}\text { Antihistamines and topical } \\
\text { corticosteroids }\end{array}$ & $\begin{array}{l}\text { Propylene glycol } \\
{[5,6]}\end{array}$ \\
\hline Anxiolytic and lubricant & Propylene glycol [7] \\
\hline Corticosteroids and NSAIDs & $\begin{array}{l}\text { Carboxymethyl- } \\
\text { cellulose [3] }\end{array}$ \\
\hline $\begin{array}{l}\text { Lubricant, stretch marks cream, } \\
\text { corticosteroid creams, and salad } \\
\text { dressings }\end{array}$ & $\begin{array}{l}\text { Propylene } \\
\text { glycol [15] }\end{array}$ \\
\hline Lubricant and corticosteroid cream & Propylene glycol [15] \\
\hline Topical medication and deodorant & Parabens [32] \\
\hline Ultrasound gels and sunscreen lotion & $\begin{array}{l}\text { Imidazolidinyl } \\
\text { urea [45] }\end{array}$ \\
\hline $\begin{array}{l}\text { Wound dressing and a thyroid } \\
\text { hormone }\end{array}$ & $\begin{array}{l}\text { Carboxymethyl- } \\
\text { cellulose [3] }\end{array}$ \\
\hline
\end{tabular}

Abbreviation: NSAIDs, nonsteroidal anti-inflammatory drugs. testing to both the anesthetic and SMB yielded delayed positive responses.

- A case of a systemic DHR following a subcutaneous injection of a local SMB-containing anesthetic has been described [14]. The patient developed a generalized eczematous rash on the trunk and limbs 3 days after the injection. Patch testing with SMB was positive.

\section{Lubricants \\ Propylene Glycol}

Three cases of patients who acquired ACD from different types of exposure to the lubricant K-Y Jelly (PG-containing) have been reported [15]. In the first 2 cases, the patients also experienced DHRs with other unrelated products due to PG (Table 2):

- The reactions reported were severe vulvitis after contact with the lubricant, severe dermatitis after the application of a cocoa butter product on the abdomen to prevent stretch marks, and dermatitis flares after the application of certain corticosteroid creams and the ingestion of salad dressings containing PG.

Table 3. Links to the PubChem Database of the National Center for Biotechnology Information (NCBI-PCD) for the Description of the Excipients Involved in the Delayed Hypersensitivity Reactions Reported

Excipient

Ascorbyl tetraisopalmitate

Benzalkonium chloride

Benzyl alcohol

Carboxymethylcellulose

Cetostearyl alcohol

Chlorocresol

Colloidal silica

Colophonium

Dioctyl sodium sulfosuccinate

EDTA

Formaldehyde

1,2,6-Hexanetriol

Imidazolidinyl urea

Isopropyl palmitate

Metacresol

Methyldibromo glutaronitrile

Polyethylene glycol

Propyl gallate

Propylene glycol

Sodium metabisulfite

Sodium sulfite

Sorbitan sesquioleate

Sunset Yellow

Thimerosal https://pubchem.ncbi.nlm.nih.gov/compound/10260680

https://pubchem.ncbi.nlm.nih.gov/compound/13740

https://pubchem.ncbi.nlm.nih.gov/compound/244

https://pubchem.ncbi.nlm.nih.gov/compound/24748

https://pubchem.ncbi.nlm.nih.gov/compound/62238

https://pubchem.ncbi.nlm.nih.gov/compound/1732

https://pubchem.ncbi.nlm.nih.gov/compound/24261

https://pubchem.ncbi.nlm.nih.gov/substance/121147430

https://pubchem.ncbi.nlm.nih.gov/compound/23673837

https://pubchem.ncbi.nlm.nih.gov/compound/6049

https://pubchem.ncbi.nlm.nih.gov/compound/712

https://pubchem.ncbi.nlm.nih.gov/compound/7823

https://pubchem.ncbi.nlm.nih.gov/compound/38258

https://pubchem.ncbi.nlm.nih.gov/compound/8907

https://pubchem.ncbi.nlm.nih.gov/compound/342

https://pubchem.ncbi.nlm.nih.gov/compound/61948

https://pubchem.ncbi.nlm.nih.gov/compound/174

https://pubchem.ncbi.nlm.nih.gov/compound/4947

https://pubchem.ncbi.nlm.nih.gov/compound/1030

https://pubchem.ncbi.nlm.nih.gov/compound/656671

https://pubchem.ncbi.nlm.nih.gov/compound/24437

https://pubchem.ncbi.nlm.nih.gov/compound/6433515

https://pubchem.ncbi.nlm.nih.gov/compound/17730

https://pubchem.ncbi.nlm.nih.gov/compound/16684434 
Table 4. Concentrations Used to Perform the Skin Tests With Each Excipient

\begin{tabular}{|c|c|c|}
\hline Excipient & Intradermal Test & Patch Test \\
\hline Ascorbyl tetraisopalmitate & & $0.05 \%$ liquid paraffin or aq $[25]$ \\
\hline BAC & & $0.1 \%$ aq $[8] ; 1: 750,1: 1000$ aq $[18]$ \\
\hline $\mathrm{BnOH}$ & & $5 \%$ pet $[24,26]$ \\
\hline $\mathrm{CMC}$ & $1 \mathrm{mg} / \mathrm{ml}[3]$ & Pure, $30 \%$ aq and $30 \%$ pet [3] \\
\hline Cetostearyl alcohol & & $1 \%, 2 \%$, and $5 \%$ pet $[27]$ \\
\hline Chlorocresol & & $2 \%$ pet $[28]$ \\
\hline Colloidal silica & & $10 \%$ pet $[17]$ \\
\hline $\begin{array}{l}\text { Colophonium and modified } \\
\text { colophonium glyceryl rosinat }\end{array}$ & & $20 \%$ pet $[52]$ \\
\hline DSS & & $1 \%$ aq $[29]$ \\
\hline EDTA & & Sodium edetate $1 \%$ aq or pet $[30]$ \\
\hline Formaldehyde & & $1 \%$ and $10 \%$ aq $[51]$ \\
\hline 1,2,6-Hexanetriol & & $0.5 \%, 2.5 \%$, and $5 \%$ pet $[31]$ \\
\hline Imidazolidinyl urea & & $2 \%$ pet $[45]$ \\
\hline Isopropyl palmitate & & $2 \%$ pet $[26]$ \\
\hline Metacresol & & $5 \%$ pet $[10]$ \\
\hline MDBGN & & $0.3 \%$ pet $[47]$ \\
\hline Parabens & & $15 \%$ unspecified vehicle [32] \\
\hline PEG & & $\begin{array}{l}\text { PEG } 300 \text { 3\% aq, PEG } 400 \text { (as is) [36]; PEGs mix 4\% pet, PEG } 3004 \% \text { pet and } \\
\text { PEG } 400 \text { (as is) [37]; PEG unspecified } 4 \% \text { pet [38] }\end{array}$ \\
\hline PG & & $\begin{array}{l}30 \% \text { aq }[6] ; 5 \% \text { aq }[7] ; 10 \% \text { aq }[28] ; 5 \% \text { pet, } 10 \% \text { glycerin or } 10 \% \text { aq }[40] ; \\
2.5 \% \text { aq }[48] ; 2 \%, 5 \%, 10 \% \text {, and } 20 \% \text { aq }[49] ; 0.1 \%, 1 \%, 10 \% \text { aq and original }[50]\end{array}$ \\
\hline SMB & & $5 \%$ pet $[13] ; 1 \% \operatorname{pet}[14]$ \\
\hline Sodium sulfite & & $0.2 \%$ and $2 \%$ aq and $0.2 \%, 2 \%$, and $5 \%$ pet $[42]$ \\
\hline SSO & & $20 \%$ pet $[43] ; 10 \%$ unspecified vehicle $[44]$ \\
\hline Thimerosal & & $0.1 \%$ pet $[22]$ \\
\hline Zinc & $\begin{array}{l}70 \mu \mathrm{g}\left(\mathrm{Zn}^{2+}\right)(\mathrm{zinc} \\
\text { lphate solution) [12] }\end{array}$ & \\
\hline
\end{tabular}

Abbreviations: aq, aqueous; $\mathrm{BAC}$, benzalkonium chloride; $\mathrm{BnOH}$, benzyl alcohol; $\mathrm{CMC}$, carboxymethylcellulose; DSS, dioctyl sodium sulfosuccinate; MDBGN, methyldibromo glutaronitrile; PEG, polyethylene glycol; pet, petrolatum; PG, propylene glycol; SMB, sodium metabisulfite; SSO, sorbitan sesquioleate.

- Severe pruritic dermatitis affecting the penis and scrotum 24 hours after the patient had intercourse with his wife, who used a vaginal lubricant. The patient had previously experienced severe ACD to halcinonide (Halog, PGcontaining).

- The third case of ACD occurred after exposure to an electrode gel (Spectra 360, PG-containing) used in a transcutaneous nerve-stimulating device and to $\mathrm{K}-\mathrm{Y}$ Jelly, which was used as substitute.

\section{Mineral Supplements}

\section{Sunset Yellow FCF}

A severe skin reaction occurred 24 hours after beginning treatment with ferrous sulphate (Ferrograd) containing Sunset Yellow FCF [16]. Patch testing performed with the European standard series yielded positive results for disperse orange, which was present in the iron formulation as Sunset Yellow.

\section{Nonsteroidal Anti-inflammatory Drugs}

\section{Colloidal Silica}

A generalized cutaneous eruption was reported with diclofenac (Voltarene). Patch testing to Voltarene was positive. The investigation of cross-reactivity with other, nonstructurally related NSAIDs showed positive patch test results with piroxicam (Piroxen), ketoprofen (Oki), and indomethacin (Indocid), in which colloidal silica was present. Patch testing to colloidal silica was positive [17]. 


\section{Ophthalmic Products}

\section{Benzalkonium Chloride}

A patient developed allergic contact conjunctivitis after treatment with 2 BAC-containing prednisolone ophthalmic solutions, first with Prednefrin and second with Inflamase Forte, which intensified the edema and the conjunctivitis [18]. Patch tests were positive in both cases and strongly positive with BAC.

Two cases of contact allergy due to BAC after treatment with dipivefrin hydrochloride (Propine) and timolol maleate (Timoptol) have been described [19]. Patch testing was positive to BAC in both.

\section{Thimerosal}

A total of 38 patients were studied because of ocular redness, irritation, and corneal changes apparently related to soft contact lens wear. Lens care solutions containing thimerosal had been used by all of the patients, and 31 responded to an ocular challenge with a thimerosal-preserved lens lubricant. Twenty-seven of these 31 also reacted to patch tests with thimerosal. Hypersensitivity to thimerosal was assumed to be responsible for the clinical findings [20,21].

In another study performed in 36 patients with thimerosalinduced follicular allergic contact conjunctivitis, 18 had been using thimerosal-containing eye drops, and 13 used thimerosalcontaining solutions for their contact lenses. All patients had positive patch test results to thimerosal [22].

- In the case of a patient with a 2-year history of episodes of dermatitis, eyelid swelling, and burning eyes treated with various eye drops without resolution, positive patch test results were recorded for thimerosal, phenylmercuric borate, and the thimerosalcontaining eye drops he used. Phenylmercuric borate hypersensitivity was considered to be due to crossreactivity with thimerosal owing to presence of a mercury compound in both allergens [23].

\section{Parenteral Medications}

\section{Benzyl Alcohol}

ACD due to benzyl alcohol has been reported after injection of sodium tetradecyl sulfate, a sclerosing agent used for the treatment of varicose veins. Patch testing with benzyl alcohol was positive [24].

\section{Topical Medications}

\section{Ascorbyl Tetraisopalmitate}

Severe ACD is reported to have been caused by ascorbyl tetraisopalmitate (an ester-modified ascorbic acid agent) contained in Atopiclair, an NSAID used for the management of atopic dermatitis [25]. Patch tests were performed with the ingredients of the cream provided by manufacturer. The patch test to ascorbyl tetraisopalmitate was positive. Vitamin $\mathrm{C}$ from food was well tolerated by the patient.

\section{Benzyl Alcohol and Isopropyl Palmitate}

A reaction was reported to amcinonide (Visderm cream) due to benzyl alcohol and isopropyl palmitate [26]. Patch testing was positive to the cream and to both excipients.

\section{Cetostearyl Alcohol}

ACD due to cetostearyl alcohol has been reported after use of hydrocortisone butyrate lipocream [27]. The only constituent of the cream to which the patient reacted (positive patch test results) was cetostearyl alcohol (Lanette O), which is a component of lanolin and cross-reacts with wool alcohols.

\section{Chlorocresol and Propylene Glycol}

Two cases of ACD with 17-clobetasol propionate (Dermovate cream) due to chlorocresol and PG were described [28]. Patch tests were positive to chlorocresol and PG.

\section{Dioctyl Sodium Sulfosuccinate}

ACD after treatment with desoximetasone (Esperson gel) due to dioctyl sodium sulfosuccinate has been reported [29]. Patch testing performed with the excipients of Esperson in both gel and ointment supplied by the manufacturer showed a strong positive result to dioctyl sodium sulfosuccinate.

\section{EDTA}

A case of ACD to EDTA used as an excipient in the formulation of Locacorten-Vioform paste was described [30]. Patch tests were positive to sodium edetate.

\section{1,2,6-Hexanetriol}

$\mathrm{ACD}$ has been reported after treatment with a fluocinonide cream due to 1,2,6-hexanetriol [31]. Patch testing performed with the ingredients of the cream confirmed a positive reaction to 1,2,6-hexanetriol.

\section{Parabens}

Three patients experienced ACD after the application of hydrocortisone acetate cream (Cortaid) containing methyl and butyl parabens [32]. Patch tests to the cream and a paraben mix (Hollister-Stier Laboratories) were strongly positive. However, the results of patch tests were negative to the various ingredients other than the parabens. As the author commented, one patient was of particular interest, since he displayed the so-called paraben paradox. The patient had applied the cream to his left axilla for irritated excoriation. He subsequently developed widespread dermatitis of the left axilla, chest, and upper abdomen requiring systemic corticosteroid treatment. Two weeks after the dermatitis had subsided, he used a deodorant spray (paraben-containing) on both axillae. Only the previously involved left axilla flared. The right axilla remained unaffected. Such an event illustrates that paraben-sensitive individuals can use paraben-containing topical applications providing the skin is not previously eczematous or has not been the site of a previous dermatitis. For this reason, in order to obtain a positive reaction in patch tests on normal skin, the author recommended a concentration of $15 \%$ parabens, at least 
15 times stronger than the paraben concentrations used in topical medications or cosmetics (usually less than 1\%) [32].

\section{Polyethylene Glycol}

The incidence of contact sensitivity to polyethylene glycol (PEG) of different molecular weights in 120 patients with suspected sensitivity to topical medication was $6.7 \%$ [33]. In a more recent study to investigate the prevalence of ACD caused by PEG in 836 patients, $4.2 \%$ had positive patch test results to PEG; this sensitivity was almost exclusively associated with allergy to nitrofurazone [34].

In relation to nitrofurazone preparations, several cases of reaction have been described after the use of Furacin (PEGcontaining):

- ACD due to PEG was reported in 2 patients [35]. Patch test results to PEG 300 and 400 were strongly positive.

- A case of eczema following the use of Furacin was described [36]. Patch test results to PEG 300 and 400 were positive.

- A case of worsening dermatitis after the application of Furacin was described [37]. Patch test results to PEG mix, PEG 300, and PEG 400 were positive.

- Five cases of ACD with local eczematous lesions 24-48 hours after application of Furacin were reported [38]. The results of the patch test to PEG were positive in 3 patients.

\section{Propyl Gallate}

A case of ACD due to propyl gallate contained in desonide cream (Locapred) was described [39]. Patch test results were positive to both the cream and propyl gallate.

\section{Propylene Glycol}

Three cases of local ACD to acyclovir cream (Zovirax) have been described [40]. Patch test results were positive to the entire product and negative to acyclovir. As for patch testing with $\mathrm{PG}$, the results were negative for 2 patients, one at a concentration of $2 \%$ and the other at a concentration of $5 \%$ in petrolatum (pet), although the result was positive for the first patient at $5 \%$ pet and the second at $10 \%$ glycerin. Patch tests performed in a third patient were positive to $\mathrm{PG}$ both at $5 \%$ pet and $10 \%$ aqueous (aq). These cases illustrate the frequency of false-negative reactions to $\mathrm{PG}$, suggesting that $\mathrm{PG}$ should be used at concentrations of $10 \%-20 \%$ or in vehicles other than pet such as glycerin or aq solution.

\section{Sodium Metabisulfite}

Two cases of ACD due to SMB as a compound of Trimovate cream were described [41]. Patch testing with SMB was positive in both patients.

\section{Sodium Sulfite}

A case of ACD due to sodium sulfite in a ketoconazole cream (Nizoral) has been reported [42]. Patch test results were strongly positive to the cream, to an identical control cream base (without the active ingredient ketoconazole), and to sodium sulfite.

\section{Sorbitan Sesquioleate}

In a study to investigate the relevance of sorbitan sesquioleate (SSO) as a sensitizer performed with 112 dermatitis patients, $8.9 \%$ had positive patch test results to $\mathrm{SSO}, 0.9 \%$ to sorbitan mono-oleate, and $1.8 \%$ to both. Of the SSO-positive patients, $75 \%$ were using topical corticosteroid preparations emulsified with sorbitan derivatives or sorbitol, and $15.4 \%$ of the sorbitan-positive patients exhibited concurrent corticosteroid allergy, thus confirming the association between sorbitan emulsifiers, use of corticosteroids, and development of ACD [43].

In this sense, a case of ACD to corticosteroid preparations was described in a patient with a history of intolerance to various topical preparations [44]. Patch test results were positive to Dermovate ointment and cream, with an irritant reaction to Betnovate $\mathrm{N}$ ointment. In patch testing with the constituents of the 3 preparations, only the result to SSO was positive.

\section{Ultrasound Gels}

\section{Imidazolidinyl Urea}

DHRs due to imidazolidinyl urea with unrelated products were reported after the first application of ultrasound gel (Meditec SRL) in a patient who had previously reacted to sunscreen lotion (Avon) [45] (Table 2). Patch test results were positive with triethanolamine, the gel, and the sunscreen (both containing imidazolidinyl urea), and those with the components of the sunscreen provided by the manufacturer were positive to triethanolamine and imidazolidinyl urea.

\section{Methyldibromo Glutaronitrile}

Reactions to methyldibromo glutaronitrile have been reported in 2 patients after application of gels containing the preservative Euxyl K 400 (methyldibromo glutaronitrilecontaining). For one patient, the result of SPT with the gel was negative but the patch test results with gel and Euxyl K 400 were positive [46]. In the second patient, patch test results were positive to Euxyl K 400, methyldibromo glutaronitrile, and the gel, which was confirmed to contain Euxyl K 400 by the manufacturer [47].

\section{Propylene Glycol}

- In ACD after application of Aquasonic 100 gel (PGcontaining), patch testing was positive to $\mathrm{PG}$ [48].

- In a case of eczematous local reaction after application of Geleco gel (PG-containing), patch testing performed with the gel and its preservatives was positive for PG [49].

- Patch testing to assess ACD after application of Ultra/ Phonic Conductivity Gel was positive for the gel, its PG compounds, and a commercial PG [50].

\section{Vaccines}

\section{Formaldehyde}

Patch testing was performed to assess systemic ACD on the anterior chest and shoulders 48 hours after intramuscular 
injection of the influenza vaccine Agriflu (formaldehydecontaining) in the right deltoid muscle. The result was positive for formaldehyde [51].

\section{Wound Dressings}

\section{Carboxymethylcellulose}

DHR with unrelated products due to CMC [3] (Table 2) was reported in a patient who developed chronic generalized urticaria after application of a wound dressing (CMCcontaining) for leg ulcers. Chronologically, the urticaria appeared when pills containing levothyroxine (a thyroid hormone) had been introduced. Intradermal testing with CMC was positive.

\section{Colophonium}

ACD was reported to be due to a modified colophonium present in a hydrocolloid dressing (Combiderm) [52]. Patch testing was positive for this dressing and for a modified colophonium derivative, glyceryl rosinate, but not for the unmodified gum rosin or colophonium $20 \%$ pet as in the standard series. The reaction to glyceryl rosinate probably represents cross-sensitivity with the modified colophonium derivative used in Combiderm, the presence (but not the exact nature) of which was shown by the manufacturer. The authors concluded that in cases where ACD from hydrocolloid dressings is suspected and colophonium test results are negative, patch testing with modified colophonium derivatives should be performed. Furthermore, as the complete composition of wound dressings is often unknown, it is necessary to advocate mandatory labelling of the products used in these and all other medical devices.

\section{Conclusions}

The number and variety of reported cases of DHRs caused by excipients highlights the importance of listing all the excipients contained in the formulation of a medication in the package insert, thus obviating the need to request the list of compounds from the manufacturer. Accurate labeling of the preparations and standardization of excipient nomenclature could facilitate the diagnosis of allergic reactions and the implementation of safe avoidance strategies to prevent future reactions in sensitized patients.

Finally, it would be very useful to provide to excipientallergic patients with a list of commercial products that contain the trigger component, as well as alternatives, since the excipients may be present in drugs that have to be administered over a patient's lifetime.

\section{Funding}

The authors declare that no funding was received for the present study.

\section{Conflicts of Interest}

The authors declare that they have no conflicts of interest.

\section{References}

1. European Medicines Agency. Doc. Ref. EMEA/CHMP/ QWP/396951/2006. London, 19 June 2007.

2. Barbaud A. Place of excipients in systemic drug allergy. Immunol Allergy Clin N Am. 2014;34:671-9.

3. Barbaud A, Waton J, Pinault AL, Bursztejn AC, Schmutz JL, Tréchot $P$. Cutaneous adverse drug reactions caused by delayed sensitization to carboxymethylcellulose. Contact Dermatitis. 2011;64:294-7.

4. McGowan MA, Scheman A, Jacob SE. Propylene Glycol in Contact Dermatitis: A Systematic Review. Dermatitis. 2018;29:6-12.

5. McEnery-Stonelake M, Silvestri DL. Contact allergens in oral antihistamines. Dermatitis. 2014;25:83-8.

6. Tocci EM, Robinson A, Belazarian L, Foley E, Wiss K, Silvestri DL. Excipients in Oral Antihistamines Can Perpetuate Allergic Contact Dermatitis. Pediatr Dermatol. 2015;32:e242-4.

7. Fisher AA. Systemic contact dermatitis due to intravenous Valium in a person sensitive to propylene glycol. Cutis. 1995;55:327-8.

8. Lechien JR, Costa de Araujo P, De Marrez LG, Halloy JL, Khalife $M$, Saussez S. Contact allergy to benzalkonium chloride in patients using a steroid nasal spray: A report of 3 cases. Ear Nose Throat J. 2018:97(1-2):E20-E22.

9. Ghazavi MK, Johnston GA. Insulin allergy. Clin Dermatol. 2011;29:300-5.

10. Clerx V, Van Den Keybus C, Kochuyt A, Goossens A. Drug intolerance reaction to insulin therapy caused by metacresol. Contact Dermatitis. 2003;48:162-3.

11. Kim D, Baraniuk J. Delayed-type hypersensitivity reaction to the meta-cresol component of insulin. Ann Allergy Asthma Immunol. 2007:99:194-5.

12. Feinglos $M N$, Jegasothy BV. Insulin allergy due to zinc. Lancet. 1979;1:122-4.

13. Dooms-Goossens $A$, de Alam AG, Degreef $H$, Kochuyt $A$. Local anesthetic intolerance due to metabisulfite. Contact Dermatitis. 1989;20:124-6.

14. Guha-Niyogi B, Sabroe R, Holden C. An unusual case of a systemic delayed hypersensitivity reaction to sodium metabisulfite. Contact Dermatitis. 2018;79:246-7.

15. Fisher AA, Brancaccio RR. Allergic contact sensitivity to propylene glycol in a lubricant jelly. Arch Dermatol. 1979;115;1451.

16. Rogkakou A, Guerra L, Scordamaglia A, Canonica GW, Passalacqua $G$. Severe skin reaction due to excipients of an oral iron treatment. Allergy. 2007;62:334-5.

17. Ben Fredj $N$, Ben Fadhel $N$, Chaabane A, Chadly $Z$, Ben Romdhane $H$, Boughattas A, et al. Colloidal silica-induced hypersensitivity: myth or reality. Int J Clin Pharm. 2016;38:7-9.

18. Fisher AA, Stillman MA. Allergic contact sensitivity to benzalkonium chloride. Cutaneous, ophthalmic, and general medical implications. Arch Dermatol. 1972;106:169-71.

19. Chiambaretta F, Pouliquen P, Rigal D. Allergy and preservatives. Apropos of 3 cases of allergy to benzalkonium chloride. J Fr Ophtalmol. 1997;20:8-16.

20. Wilson LA, McNatt J, Reitschel R. Delayed hypersensitivity to thimerosal in soft contact lens wearers. Ophthalmology. 1981;88:804-9. 
21. Rietschel RL, Wilson LA. Ocular inflammation in patients using soft contact lenses. Arch Dermatol. 1982;118:147-9.

22. Tosti A, Tosti G. Thimerosal: a hidden allergen in ophthalmology. Contact Dermatitis. 1988;18:268-73.

23. Iliev D, Wüthrich B. Conjunctivitis to thimerosal mistaken as hay fever. Allergy. 1998;53:333-4.

24. Shmunes E. Allergic dermatitis to benzyl alcohol in an injectable solution. Arch Dermatol. 1984;120:1200-1.

25. Assier H, Wolkenstein P, Grille C, Chosidow O. Contact dermatitis caused by ascorbyl tetraisopalmitate in a cream used for the management of atopic dermatitis. Contact Dermatitis. 2014;71:60-1.

26. Lazzarini S. Contact allergy to benzyl alcohol and isopropyl palmitate, ingredients of topical corticosteroid. Contact Dermatitis. 1982;8:349-50.

27. Marston S. Contact dermatitis from cetostearyl alcohol in hydrocortisone butyrate lipocream, and from lanolin. Contact Dermatitis. 1991;24:372.

28. Oleffe JA, Blondeel A, de Coninck A. Allergy to chlorocresol and propylene glycol in a steroid cream. Contact Dermatitis. 1979:5:53-4.

29. Lee AY, Lee KH. Allergic contact dermatitis from dioctyl sodium sulfosuccinate in a topical corticosteroid. Contact Dermatitis. 1998;38:355-6.

30. De GrootAC. Contact allergy to EDTA in a topical corticosteroid preparation. Contact Dermatitis. 1986;15:250-2.

31. Miura $Y$, Hata $M$, Yuge $M$, Numano $K$, Iwakiri K. Allergic contact dermatitis from 1,2,6-hexanetriol in fluocinonide cream. Contact Dermatitis. 1999;41:118-9.

32. Fisher AA. Cortaid cream dermatitis and the "paraben paradox". J Am Acad Dermatol. 1982;6:116-7.

33. Bajaj AK, Gupta SC, Chatterjee AK, Singh KG. Contact sensitivity to polyethylene glycols. Contact Dermatitis. 1990:22:291-2.

34. Özkaya E, Kılıç S. Polyethylene glycol as marker for nitrofurazone allergy: 20 years of experience from Turkey. Contact Dermatitis. 2018;78:211-5.

35. Fisher AA. Immediate and delayed allergic contact reactions to polyethylene glycol. Contact Dermatitis. 1978;4:135-8.

36. Stenveld HJ, Langendijk PN, Bruynzeel DP. Contact sensitivity to polyethylene glycols. Contact Dermatitis. 1994;30:184-5.

37. Guijarro SC, Sánchez-Pérez J, García-Díez A. Allergic contact dermatitis to polyethylene glycol and nitrofurazone. Am J Contact Dermat. 1999;10:226-7.

38. Prieto A, Baeza ML, Herrero T, Barranco R, De Castro FJ, Ruiz $J$, et al. Contact dermatitis to Furacin. Contact Dermatitis. 2006;54:126.

39. Hernández N, Assier-Bonnet H, Terki N, Revuz J. Allergic contact dermatitis from propyl gallate in desonide cream (Locapred). Contact Dermatitis. 1997;36:111.
40. Claverie F, Giordano-Labadie F, Bazex J. Contacteczema induced by propylene glycol. Concentration and vehicle adapted for patch tests. Ann Dermatol Venereol. 1997;124:315-7.

41. Tucker SC, Yell JA, Beck MH. Allergic contact dermatitis from sodium metabisulfite in Trimovate cream. Contact Dermatitis. 1999;40:164.

42. Vissers-Croughs KJ, van der Kley AM, Vulto AG, Hulsmans RF. Allergic contact dermatitis from sodium sulfite. Contact Dermatitis. 1988; 18:252-3.

43. Asarch A, Scheinman PL. Sorbitan sesquioleate, a common emulsifier in topical corticosteroids, is an important contact allergen. Dermatitis. 2008;19:323-7.

44. Green C, Kenicer KJ. A case of "contact allergy to corticosteroid". Contact Dermatitis. 1993;28:39-40.

45. Ando M, Ansótegui J, Muñoz D, Fernández de Corres L. Allergic contact dermatitis from imidazolidinyl urea in an ultrasonic gel. Contact Dermatitis. 2000;42:109-10.

46. Gebhart M, StuhlertA, Knopf B. Allergic contact dermatitis due to Euxyl K 400 in an ultrasonic gel. Contact Dermatitis. 1993;29:272.

47. Erdmann SM, Sachs B, Merk HF. Allergic contact dermatitis due to methyldibromo glutaronitrile in Euxyl $\mathrm{K} 400$ in an ultrasonic gel. Contact Dermatitis. 2001;44:39-40.

48. Ayadi M, Martin P, Bergoend H. Contact dermatitis to a carotidian Doppler gel. Contact Dermatitis. 1987;17:118-9.

49. Gonzalo MA, de Argila D, García JM, Alvarado MI. Allergic contact dermatitis to propylene glycol. Allergy. 1999;54:82-3.

50. Horiguchi Y, Honda T, Fujii S, Matsushima S, Osaki Y. A case of allergic contact dermatitis from propylene glycol in an ultrasonic gel, sensitized at a leakage skin injury due to transcatheter arterial chemoembolization for hepatocellular carcinoma. Int J Dermatol. 2005;44:681-3.

51. Kuritzky LA, Pratt M. Systemic Allergic Contact Dermatitis after Formaldehyde-Containing Influenza Vaccination. J Cutan Med Surg. 2015;19:504-6.

52. Pereira TM, Flour M, Goossens A. Allergic contact dermatitis from modified colophonium in wound dressings. Contact Dermatitis. 2007; 56:5-9.

\section{- Manuscript received January 7, 2020; accepted for publication April 24, 2020.}

\section{María Luisa Caballero}

Department of Allergy

Hospital La Paz Institute for Health Research (IdiPAZ)

Paseo de la Castellana, 261

28046 Madrid, Spain

E-mail: mlcsoto@hotmail.com 